\title{
On the Cover of This Issue: Dr. Debjoy Mallick Running Experiments Within the Laser Shock Facility at the Hopkins Extreme Mechanics Institute, Directed by Professor K.T. Ramesh
}

This facility is able to achieve high pressures and ultrahigh strain rates for relatively short timesand can be used to study the equation of state, to evaluate spall and other high-rate damageprocesses, and to interrogate laser-matter interactions.
Publisher's Note Springer Nature remains neutral with regard to jurisdictional claims in published maps and institutional affiliations.

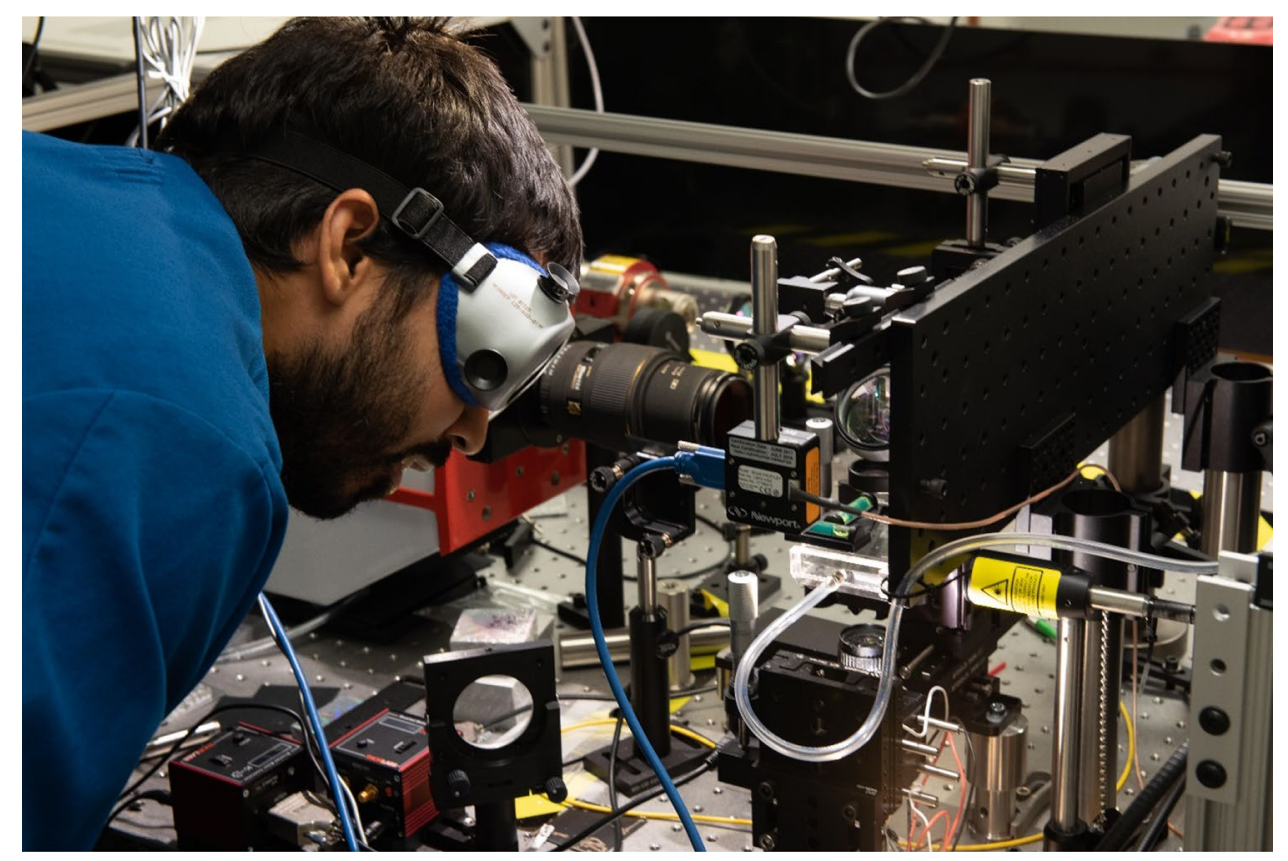

